\title{
ANALOGIA E HERMENÊUTICA: EM BUSCA DE UMA EPISTEMOLOGIA ANALÓgICA PARA O TEXTO NARRATIVO BÍBLICO E SUA TEOLOGIA
}

\begin{abstract}
Analogy and hermeneutics: Towards an analogical epistemology
\end{abstract} for the narrative biblical text and its theology

\author{
George Reyes*
}

RESUmO: A pesquisa e a aplicação do modelo analógico ao texto narrativo bíblico pode ajudar a hermenêutica bíblica não só a beneficiar-se da melhor contribuição das tendências epistemológicas modernas e pós-modernas, mas também a evitar a dura univocidade objetivista da primeira e a dura equivocidade subjetivista da segunda tendência. A principal razão é que esse modelo analógico procura colocarse prudentemente entre essas duas tendências, sem predominância de nenhuma delas.

Palavras-Chave: Narrativa, Analogia, Hermenêutica, Epistemologia, Beuchot.

ABSTRACT: The research and application of the analogical model to the biblical narrative text can help biblical hermeneutics not only to benefit from the best contribution of modern and postmodern epistemological tendencies, but also to avoid the hard objectivist univocality of the first and the hard subjectivist equivocality of the second trend. The main reason is that this analogical model seeks to place itself prudentially between these two tendencies, without predominance of any of them.

KeYwords: Narrative, Analogy, Hermeneutics, Epistemology, Beuchot.

\footnotetext{
* Seminario Todas las Naciones (Ciudad Juárez, Chihuahua, MÉXICO). Artigo submetido a avaliação no dia 03/12/2010 e aprovado para publicação no dia 16/12/2010.
} 


\section{Introdução}

Como observa Chaves Tesser ${ }^{1}$, no discurso ou pensamento crítico contemporâneo é possível agora não apenas ouvir ou ler neologismos e muitos outros termos equívocos, mas também constatar diferentes tendências, por exemplo, literárias, sociais, psicológicas, científicas com as quais, queiramos ou não, devemos aprender a conviver e a dialogar criticamente. O mesmo se dá no campo da hermenêutica. Não é por casualidade, então, que, a partir de seu próprio contexto, o hermeneuta francês Paul Ricoeur ${ }^{2}$, tenha-se referido ao conflito que se pode detectar hoje entre as diversas hermenêuticas; é que cada tendência nesse campo é articulada e praticada segundo a mentalidade epistemológica prevalecente até hoje para a qual cada intérprete se incline, seja esta moderna ou pós-moderna ${ }^{3}$.

Ainda que pudéssemos beneficiar-nos de ambas as epistemologias - da moderna e da pós-moderna ${ }^{4}$-, elas tendem respectivamente para um duro fundacionismo e antifundacionismo epistemológico que, entre outras coisas, promove a vontade de poder e impede frequentemente o diálogo na tarefa de interpretação. Como, pois, beneficiar-nos criticamente, na interpretação bíblica $^{5}$, das contribuições válidas de ambas? Como evitar nessa tarefa a tendência dura univocista-objetivista totalitária e a equivocista-subjetivista cética, que caracterizam respectivamente as interpretações moderna e pósmoderna?

Considero que, na hermenêutica bíblica, a resposta não pode ser outra a não ser esta: por meio da exploração do texto sagrado e da aplicação nele desse modelo, procurar prudentemente colocar-se no ponto intermediário entre as

${ }^{1}$ C. CHAVES TESSER, "El debate teórico actual", in J.L. GÓMEZ-MARTÍNEZ (org.), Más allá de la pos-modernidad: El discurso antrópico y su praxis en la cultura iberoamericana, Madrid: Mileto, 1999, p. 7.

${ }^{2}$ P. RICOEUR, El conflicto de las interpretaciones: Ensayos de hermenéutica, Traducción del original francés por A. Falcón, Buenos Aires: Fondo de Cultura Económica, 2003.

${ }^{3}$ Por ser o tema de discussão principalmente neste capítulo, esclarecerei de um modo simplista que por "epistemologia" entendo aqui a perspectiva enquanto o modo como conhecemos ou deveríamos conhecer. Em nosso caso, procuramos responder a uma pergunta difícil de responder satisfatoriamente: Como se conhece ou se entende, ou como se deveria conhecer ou entender um texto?

${ }^{4}$ Por exemplo, apesar da resistência hodierna contra a argumentação intelectual, considero que uma contribuição válida da epistemologia moderna, e que se deveria resgatar, é essa argumentação. Ao lado da inferência e da suspeita, e com a ponderação deliberativa que faz dos prós e contras (ato próprio do que se chama "prudência" na tarefa de interpretação), a argumentação limita ou depura a fase intuitiva primeira da tarefa hermenêutica - como a chama Ricoeur -; assim impede que se desemboque em uma equivocidade sem controle. Mais adiante, refletiremos sobre as contribuições da pós-modernidade que deveríamos reter na tarefa de interpretação.

${ }^{5}$ Inclusive na literária, na contextual e ainda no discurso teológico. 
duas tendências epistemológicas anteriores, sem que haja predomínio de nenhuma delas ${ }^{6}$. A razão fundamental é que, além de ajudar-nos a superar os dois extremos anteriores, esse modelo nos permite uma objetividade suficiente para podermos recuperar aquilo que o autor teria tentado comunicar, ainda que não do modo como nós o tivéssemos querido; além disso, ajudar-nos-ia a identificar uma verdade textual que faça mais justiça ao texto. Esse modelo é o analógico, o qual começa a ganhar hoje um espaço cada vez maior em diversos ramos do saber ${ }^{7}$. Portanto, o resultado seria uma hermenêutica analógica bíblica que, entre outras coisas, reconhece e aceita a ingerência natural da subjetividade em si e oferece uma saída viável, a qual urge em nossos tempos pós-modernos.

Por meio de um diálogo construtivo e crítico, proponho-me, neste ensaio, explorar brevemente esse modelo epistemológico orientado à interpretação do texto bíblico narrativo. Para isso, analiso primeiramente a proposta hermenêutico-analógica no campo filosófico, tal como a expõe Mauricio Beuchot, professor da Faculdade de Filosofia e Letras da Universidade Autônoma do México (UNAM), investigador dessa mesma casa de estudos e pioneiro da proposta analógica na América Latina. Em seguida, exploro o que seria uma hermenêutica analógica bíblica. Finalmente, com base nesse modelo, e a modo de conclusão, formulo algumas implicações gerais do modelo analógico com relação ao texto narrativo.

\section{Mauricio Beuchot: um novo modelo de epistemologia hermenêutica}

Diante da crise da epistemologia univocista cientificista positivista moderna, tudo parece indicar que o mundo ocidental atualmente marcha para outro extremo promovido pela cultura pós-moderna. Essa cultura equivocista é responsável pelo relativismo niilista que vai predominando cada vez mais

\footnotetext{
${ }^{6}$ Contudo, é necessário primeiro esclarecer que essa maneira de pensar não necessariamente ignora que a analogia se caracteriza pela semelhança e pela diferença com predomínio precisamente desta última -, com suas respectivas implicações; entre essas implicações está a de reconhecer que pode existir mais de uma interpretação válida de um texto bíblico, ainda mais quando este não se refere a nenhuma doutrina essencial da fé cristã. Mas reconhecer tal coisa é diferente de identificar-se deliberadamente com o equivocismo relativista pós-moderno, o que, de algum modo, significaria renunciar à semelhança ou ao equilíbrio e alinhar-se ao pensamento ou à hermenêutica fraca, carente de sólidos fundamentos.

${ }^{7}$ Ver, na área da hermenêutica bíblica, G. REYES, "Verdad y racionalidad hermenéutica analógica: Exploración e implicaciones para la interpretación del texto bíblico", Kairós (2010/n.45) 81-108; M. BEUCHOT, Compendio de hermenéutica analógica, México: Torres, 2007, pp. 51-142, faz referência a esses outros campos do saber em que este modelo está sendo aplicado atualmente.
} 
em nossa sociedade ocidental ${ }^{8}$. Diante dessa tendência epistemológica, Beuchot ${ }^{9}$ propõe que a melhor alternativa é uma epistemologia hermenêutica analógica, ainda que, esclarece ele, esta se caracterize por ser preponderantemente aberta ${ }^{10}$. Com base nessa epistemologia, prossegue Beuchot, é possível não apenas aproximar-se mais da verdade textual, mas também restringir as interpretações infinitas que se afastam cada vez mais dessa verdade $^{11}$.

Para sustentar seu ponto de vista, Beuchot recorre a um princípio epistemológico de origem grega e medieval, o qual, segundo ele, percorreu a história e se mantém vivo no presente ${ }^{12}$. Esse princípio, afirma ele, é o analógico, que enfatiza a diferença ou a diversidade, sem, contudo, renunciar à semelhança, o que permite assim atingir certa universalização e certo equilíbrio no que se refere à objetividade.

\footnotetext{
${ }^{8}$ Deveríamos recordar que, em um sentido, o pós-modernismo hermenêutico é um movimento de protesto contra o modernismo hermenêutico e suas pretensões de cientificidade, objetividade e sentido claro e preciso; mas o problema é que se abre para o influxo excessivo do leitor ou leitora no processo de compreensão. Para uma descrição dessa epistemologia equivocista "romântica" - como a chama Beuchot - e da univocista moderna, ver o capítulo anterior dessa mesma obra; ver também $\mathrm{M}$. BEUCHOT, Perfiles esenciales de la hermenéutica, México: Universidad Nacional Autónoma de México, 2005, pp. 21-24; M. BEUCHOT et alii, Hermenéutica analógica y hermenéutica débil, México: Facultad de Filosofía y Letras, Universidad Nacional Autónoma de México, 1996, pp. 15-33; H. DE WIT, En la dispersión el texto es Patria: Introducción a la hermenéutica clásica, moderna y posmoderna, San José: Universidad Bíblica Latinoamericana, 2002, pp. 109-159.

9 M. BEUCHOT, Tratado de hermenéutica analógica: Hacia un nuevo modelo de interpretación, México: Itaca, 2005; ID., Perfiles esenciales de la hermenéutica; cf. ID., Posmodernidad, hermenéutica y analogía, México: Universidad Intercontinental, 1996. ${ }^{10}$ Isso porque, afastando-se do totalitarismo univocista, essa hermenêutica não pretende nem exige uma única interpretação que se considere válida. É que para Beuchot - temos de esclarecer já de entrada - a analogia é equivocidade ou polissemia (pluralidade de sentido) sistemática, ainda que controlável, já que, por razões que se explicarão mais adiante, ela não permite que o intérprete perca de vista os sentidos certeiros e hierarquizados de um texto; em outros termos, como o digo em seguida, para Beuchot, a analogia não se limita ao sentido unívoco (metonímia) nem ao equívoco (metáfora) do texto, ainda que tenda mais para este último.

${ }^{11}$ Essa verdade adquire, por virtude da hermenêutica analógica, um caráter distintivo, isto é, um caráter não absoluto, mas relativo, porém nunca relativista-cético. A partir daqui, no que diz respeito à proposta hermenêutica de Beuchot, limitar-me-ei às fontes assinaladas acima, razão pela qual intencionalmente evito as referências bibliográficas correspondentes, exceto quando se trate de alguma citação direta ou o que foi assinalado proceda de uma fonte diferente.

${ }^{12}$ Esse princípio, argumenta ele, está presente hoje especialmente por meio desse discurso literário que soube potencializá-lo. Esse discurso é o poético, como o de Charles Sanders Peirce, Bachelard, Rescher e do mexicano Octavio Paz; ver um resumo dessa história em BEUCHOT, Compendio de hermenéutica analógica, espec. pp. 27-37. Deveríamos ter presente que, de um modo ou de outro, através da história, esse princípio esteve presente também na hermenêutica textual, inclusive bíblica.
} 
Antes de ver em que consiste esse princípio e como ele alcançaria esse equilíbrio, é conveniente estudar resumidamente algumas propostas feitas também por Beuchot. Refiro-me ao que ele entende tanto por hermenêutica quanto por ato hermenêutico e seus passos respectivos.

\section{Hermenêutica e ato hermenêutico}

\section{Natureza, propósito e finalidade da hermenêutica}

Segundo Beuchot, a hermenêutica nasceu entre os gregos ${ }^{13}$ e pode ser definida como ciência (episteme) e, ao mesmo tempo, como arte (techne) de interpretar textos. É ciência, porque, assim como a lógica - da qual, segundo ele, a hermenêutica, de algum modo, ter-se-ia desprendido - tem princípios que a ajudam a estruturar o que vai aprendendo a respeito da interpretação dos textos. Isso quer dizer, entre outras coisas, que a argumentação intelectual tem um papel determinante nela. Por outro lado, argumenta Beuchot, ela é arte, porque, no processo de interpretação, predomina a intuição, e nele está implícito "um conjunto de regras que se vai incrementando à medida que a experiência interpretativa nos ensina e instrui, e como uma aplicação bem adaptada dos princípios e leis gerais que a hermenêutica vai agrupando enquanto ciência"14; assim, pois, ainda que Beuchot parecesse dar um

\footnotetext{
${ }^{13}$ Platão (428-347 a.C.), por exemplo, argumenta Beuchot, falava já do hermeneuta como intérprete e como exegeta dos poemas, sobretudo de Homero; devo acrescentar que esse hermeneuta e exegeta - que não era precisamente Platão, que, segundo Beuchot, inclinava-se para a hermenêutica literal - tendia a usar o método hermenêutico alegórico (altamente equivocista) em sua interpretação e exegese, o qual foi herdado pelos Padres da Igreja como Orígenes (185-255 d.C.) na Idade Antiga. Séculos depois, a hermenêutica incursiona pela modernidade - que teria que levá-la adiante com tintas de cientificismo e fazê-la decair precisamente por esse ideal extremo iluminista de ciência - para posteriormente ressurgir na linha romântica e desembocar atualmente na neorromântica da época pós-moderna, na qual sobressaem o equivocismo extremo e a universalização dela, ou seja, sua presença na filosofia, na história, na literatura, na cultura e em outros campos.

${ }^{14}$ BEUCHOT, Tratado de hermenéutica analógica, pp. 19-20. Beuchot argumenta que o fato de ser arte deve-se a que seja ciência; por isso a hermenêutica é principalmente ciência e, secundariamente, arte. Em sua opinião, outro aspecto dual da hermenêutica é evidente em sua natureza, teórica e prática ao mesmo tempo; ainda que a natureza primordial dessa disciplina seja ser teórica, dela obtém o que a fará caracterizar-se também como um saber prático; "que possa ser prática [hermenêutica utens]", argumenta ele, "deriva-se de seu ser propriamente teórica [hermenêutica docens]. Por isso, eu disse antes que é ciência e arte ao mesmo tempo"; BEUCHOT, Tratado de hermenéutica analógica, p. 23; Perfiles esenciales de la hermenéutica, pp. 13-15; cf. M. FOUCAULT, Microfísica del poder, Madrid: Piqueta, 1992. Ora, seguindo Gadamer, que propôs como esquema da hermenêutica a "prudência" (phrónesis) aristotélica, BEUCHOT, em Compendio de hermenéutica analógica, pp. 35-36, e em Hermenéutica analógica, símbolo, mito y filosofía, México: Universidad Nacional Autónoma de
} 
amplo lugar à intuição ${ }^{15}$ - contrariamente a outros hermeneutas como Gadamer -, privilegia o método na tarefa hermenêutica de interpretação.

Seguindo os hermeneutas medievais e contemporâneos, Beuchot considera que, entre os textos aos quais a hermenêutica presta muita atenção, estão os escritos, o que é a proposta tradicional; ele também inclui os hiperfrásticos, ou seja, aqueles que não apenas são maiores que a frase, mas que também, pela mesma razão, vão além da palavra e do enunciado e, além disso, caracterizam-se por serem altamente polissêmicos: os falados (Gadamer), praticados (Ricoeur) e pensados ${ }^{16}$. Ainda mais, Beuchot ${ }^{17}$ inclui o símbolo, o qual é também um texto polissêmico: pertence a vários e diversos campos de investigação e conecta duas dimensões, uma linguística e outra não linguística. Entretanto, ainda que seja polissêmico, argumenta Beuchot, o símbolo possui uma natureza analógica por excelência ${ }^{18}$. É que o símbolo,

México, 2007, pp. 77-89, sustenta que, além de ciência e arte, a hermenêutica é prudência porque, sendo esta uma virtude muito analógica - que versa sobre o que é prático e leva em conta os detalhes, privilegiando as diferenças a despeito das semelhanças e buscando os meios para chegar aos fins através da libertação - trata de encontrar um ponto médio ou moderado prudencial no processo de interpretação; e é isso, argumenta ele, o que precisamente se procura na tarefa hermenêutica: através da libertação, buscar os meios apropriados para chegar à melhor interpretação, na qual se cotejam as interpretações entre si e se opta pelas mais apropriadas. ${ }^{15}$ Isto é, aquela espécie de perspicácia com a qual todo intérprete pareceria começar sua leitura de um texto, considerada, corretamente, por alguns hermeneutas como a fase primeira do processo de interpretação. Sendo a primeira, o intérprete deve avançar à segunda (exegese), à terceira (articulação do sentido, mensagem ou referência do texto) e, finalmente, à quarta (contextualização desse sentido, mensagem ou referência). Beuchot, contudo, pareceria fazer-nos ficar nessa primeira fase, na qual, de fato, muitos intérpretes, especialmente do texto bíblico, costumam ficar.

${ }_{16}$ Nessa lista, também deveríamos incluir uma pintura artística, uma peça de teatro, uma ação significativa, o diálogo na interação educativa, o mundo - segundo os medievais e renascentistas -, e o símbolo - um mito, um rito, um poema e outros objetos, quer religiosos quer artísticos - no qual, como bem argumenta Beuchot, o que representa transmite os valores humanos e outorga identidade cultural. Ora, os textos pensados são os que mais se prestam à aplicação da transação psicanalítica, na qual, além do diálogo entre o analista e o analisado, conta a ação deste último, especialmente na relação de transferência. Não é de se estranhar que, com base na psicanálise freudiana, Beuchot ofereça um exemplo de como se aplica sua proposta analógica; ver suas obras Tratado de hermenéutica analógica, pp. 159-170; Compendio de hermenéutica analógica, pp. 71-90.

${ }_{17}$ BEUCHOT, Hermenéutica analógica, símbolo, mito y filosofía; cf. P. RICOEUR, Teoría de la interpretación: Discurso y excedente de sentido, Traducción del original francés por Siglo XXI, México: UIA / Siglo XXI, 2006, pp. 58-82.

${ }^{18}$ Isso porque o símbolo é bifásico, ou seja, tem dois rostos: um projetado para a metáfora, e o outro, para a metonímia. O primeiro conduz ao subjetivismo, e o segundo, a certo grau de objetividade que é o que lhe impede deixar-se influenciar ou perverter facilmente pelo subjetivismo; por isso, quando o intérprete permanece no sentido metafórico do símbolo, este adquire um rosto de "ídolo", e quando sucede o contrário, adquire um rosto de "ícone". Por isso, se deveriam explorar ambos os sentidos do símbolo, o metafórico (aquele recôndito e profundo) e o metonímico (aquele direto e referencial ou o assunto a que se refere). A exploração de ambos os sentidos é possível por meio da analogia. 
prossegue ele, tem um componente icônico, pois "não é apenas o signo mais rico, porque sempre tem múltiplos significados, também é um signo que manifesta uma semelhança com o significado, por isso era chamado 'signo imagem', ou seja, contém algo icônico"119. Por isso, opina este autor, o ícone é o signo híbrido, o análogo e o que ajuda a conhecer o texto.

Beuchot opina que todos os textos anteriores são os que mais demandam do exercício da interpretação e são aqueles em que a hermenêutica analógica, associada à sutileza ${ }^{20}$, vê-se obrigada a interpretar por serem tanto seu principal objeto de atenção quanto por serem os mais difíceis de interpretar, e de fazê-lo frequentemente com base nos parâmetros da ciência ou da razão. É apenas com base na analogia, prossegue Beuchot, que se pode resgatar, de todos eles, sua riqueza e plenitude, já que, de outro modo, no caso do símbolo, "ficaríamos a meio caminho: com o regozijo da metáfora, mas sem a segurança cognoscitiva da metonímia"21. Daí sustentar Beuchot que a hermenêutica nasce onde se dá a polissemia, e que o objetivo dela é não apenas a contextualização aproximada do texto - situá-lo, na medida do possível, dentro de seu contexto de vida e produção original, aquilo que está "por trás" do texto -, mas também a compreensão intelectiva, tradutiva, explicativa ${ }^{22} \mathrm{ou}$, acrescentando, interpretativa de seu mundo (fictício ou

\footnotetext{
${ }^{19}$ BEUCHOT, Hermenéutica analógica, símbolo, mito y filosofía, p. 9.

${ }^{20}$ Isto é, aquela perspicácia prudencial de libertação, juízo e decisão, prevalecente na hermenêutica renascentista, medieval e, acrescentaria, textual contemporânea. Ela consistia e consiste em que o bom intérprete procura, na medida do possível - e de um modo analógico -, não o sentido superficial, mas o profundo, o oculto, o melhor, o autêntico, vinculado com a intenção do autor e plasmado no texto que ele produziu. Assim, pareceria que Beuchot identifica a sutileza com a prudência aristotélicogadamerista ou com a intuição; ver sua obra Hermenéutica analógica, símbolo, mito y filosofía, p. 59. Ver outras coisas em que essa sutileza consistia, em BEUCHOT, Tratado de hermenéutica analógica, p. 24, nota 13; Perfiles esenciales de la hermenéutica, pp. 11-12.

${ }_{21}$ BEUCHOT, Hermenéutica analógica, símbolo, mito y filosofía, p. 33. A metáfora e a metonímia são figuras literárias de significado. A primeira tende a ser equívoca, e a segunda, unívoca. É por isso que, em concordância com Beuchot, existe a necessidade de equilibrar uma com a outra. É desse modo que a hermenêutica analógica ultrapassa as hermenêuticas metafóricas como a de Ricoeur (em Teoría de la interpretación) e inclusive as intuitivistas e alegoristas de certos contextos eclesiásticos.

${ }^{22}$ Beuchot rechaça a oposição entre compreensão e explicação estabelecida por Dilthey (finais do século XIX), o qual, fazendo uma divisão dos saberes em ciências da natureza e ciências do espírito, sustentava que as primeiras procuram explicar, e as segundas, compreender, e que ambas trabalham com metodologias irreconciliáveis. Em lugar disso, ele propõe corretamente uma relação dialética entre esses polos dentro do mesmo processo hermenêutico, tal como o fizeram Heidegger e seu discípulo Gadamer, com o fim de desconstruir aquela tendência prevalecente talvez até hoje: aceitar como ciência somente aquelas disciplinas que se dedicam a explicar, especialmente segundo o modelo da física.
} 
real $)^{23}$ e da mensagem ou da intenção do autor, como resultado dessa contextualização. Segundo esse mesmo autor, essa compreensão será melhor, se o leitor conhece a identidade dos destinatários, seu momento histórico, seu condicionamento cultural, bem como o propósito do autor. Além disso, sustenta Beuchot, essa compreensão será melhor, se o leitor está consciente do que realmente ele é: um leitor; mas é um leitor - acrescentaríamos nós - que sabe lidar da melhor maneira com sua subjetividade e com o conhecimento antecipado do texto, porque reconhece seus próprios interesses, inclusive políticos e religiosos, na hora de interpretá-lo.

Como tarefa interpretativa, a hermenêutica procura e tem como finalidade compreender ou conhecer, traduzir ou fazer entender e normatizar o ope$\operatorname{rar}^{24}$. Essa é a razão, pensa este autor, por que ela está relacionada intimamente com a ética - começando com a do próprio leitor - que é o que caracteriza precisamente o sentido analógico. Além disso, continua Beuchot, essa relação com a ética conecta-a com a hermenêutica anagógica ou mística, isto é, com aquela que procura oferecer um projeto para o futuro e abrir um espaço para a esperança política ${ }^{25}$. É que, opina Beuchot ${ }^{26}$, a hermenêutica não pode ignorar nem destruir a ontologia ou a metafísica que está atenta ao contexto ${ }^{27}$, à situação, ao tempo, à história ou, em suma, ao

${ }^{23}$ Evidentemente, quando fala de "mundo" Beuchot não se estaria referindo ao "mundo literário" do texto (sua realidade total subjacente), mas ao conjunto de referências abertas pelos textos descritivos e ostensíveis ou não descritivos, como são os poéticos (cf. RICOEUR, Teoría de la interpretación, pp. 46-50). Segundo ele, como já brevemente mencionei, a hermenêutica deve ter, hoje mais que nunca - quando se questionam ou se rechaçam os moldes racionalistas de argumentação - uma abertura analógica. Esta abertura deve ser não somente, como o foi em suas origens, à argumentação, sobretudo retórica, mas também à metafísica (conceito que, em sua perspectiva, inclui Deus); daí que o mais natural é que, ao falar de "mundo", Beuchot, do mesmo modo que Heidegger, refira-se a essa abertura referencial dos textos descritivos e ostensíveis. Contudo, deve-se recordar que o "mundo" de um texto pode também manifestar abertura referencial.

${ }^{24}$ Isso é o que perseguem, por exemplo, a filológica e historiográfica, a teatral e musical, e a jurídica e a teológica, respectivamente. Por isso, Beuchot propõe antes três tipos de tradução, segundo três finalidades que lhe poderiam ser atribuídas: compreensiva, reprodutiva e aplicativa. Além disso, segundo ele (em Perfiles esenciales de la hermenéutica, pp. 13-14) - e como já se viu - ela deve ser entendida como uma tarefa, ao mesmo tempo, teórica e prática. Destarte, a hermenêutica está longe de ser uma ciência puramente teórica ou uma ciência puramente prática. Ela combina analogicamente ambos os aspectos, a teoria e a prática.

${ }^{25}$ BEUCHOT et alii, Hermenéutica analógica y hermenéutica débil, pp. 54, 57. "Uma hermenêutica analógica", propõe Beuchot, "é chamada a ser anagógica em sua culminação"; Hermenéutica analógica y hermenéutica débil, p. 54. Essa foi sua resposta à crítica que G. Vattimo lhe fizera, ainda que seja quem ele siga também nesse aspecto da hermenêutica; ver essa crítica e uma descrição sintética da hermenêutica anagógica e de suas implicações nas páginas 21-41 dessa mesma obra anterior.

${ }^{26}$ BEUCHOT et alii, Hermenéutica analógica y hermenéutica débil, p. 54.

${ }^{27}$ Assim como a filosofia analítica, Beuchot usa ambos os conceitos como sinônimos - ou seja, entende a ontologia como metafísica, esta última incluindo a transcendência divina -, e vê a urgência dessa recuperação devido ao fato de que, na hermenêutica, 
ser humano em geral e a seus direitos, que o dignificam. Ao contrário, recuperá-la-á analogicamente. Em suas próprias palavras:

[A] hermenêutica deve abrir as perspectivas ontológicas e metafísicas, como o fez Lévinas, mas com uma medida proporcional que nos impeça de ficar sem ontologia alguma, sem suficiente metafísica. E requeremos um fundamento fraco, ou seja, analógico, para a hermenêutica mesma, para que não nos afogue no relativismo que não conduz a parte alguma. Em todo caso, seria, como se disse, uma ontologia analógica, a qual é muito parecida com o que pretende Vattimo com sua ontologia fraca, já que está consciente de que uma negação forte da metafísica conduziria a uma postura igualmente forte e em contradição com seu pensamento fraco.

Assim, pois, poderíamos argumentar duas coisas importantes sobre a perspectiva de Beuchot. A primeira é que sua hermenêutica desemboca finalmente no contexto, e isso faz com que ela seja contextual e solidária, ainda que ele não o sublinhe como, ao contrário, o faz Vattimo, o qual argumenta colocando-se ao lado dos marginalizados, isto é, ao lado da diferença, contra a identidade homogeneizada que procura a globalização atual. A segunda é que, com sua defesa da metafísica na hermenêutica, Beuchot situa-se em linha com Derrida, Foucault, Trías, com os seguidores de Wittgenstein e com Vattimo, os quais, a partir de muitas frentes, a seu próprio modo e através da hermenêutica, pedem a recuperação da metafísica, ainda que esta, do mesmo modo que a hermenêutica em si, seja fraca e distinta da postura univocista moderna, prepotente e violenta, que eles procuram combater ${ }^{28}$.

Parece que o que foi dito anteriormente é o que motiva Beuchot a lutar pela recuperação de uma metafísica análoga, que inclusive tenha que ver com o símbolo, ou seja, uma metafísica simbólica que procure recuperar a experiência vivencial - sentimental ou emocional - e intelectiva ${ }^{29}$. $\mathrm{O}$ resultado seria uma hermenêutica metafísica analógica que, não sendo duramente racionalista, respeita "as diferenças, sem cair, porém, no equivocismo... e

e a partir de Heidegger, a ontologia ou a metafísica vieram decaindo no pensamento hermenêutico-filosófico dos últimos anos por sua tendência ateia e por ter-se tornado irrelevante para o ser: 1) porque se sublinha na hermenêutica apenas sua linguisticidade, e 2) porque se proclama tanto a ausência de fundamentos quanto a presença de um relativismo forte. Outros opinam que isso se deva ao fato de ela ter sido tão violenta a ponto de ter produzido o holocausto de Auschwitz. É o caso da hermenêutica moderna.

${ }^{28}$ Derrida, por exemplo, enfatiza a metafísica da presença (ilusão de possuir o sentido ou de permanecer no ser), a qual, segundo ele, plenifica; ao contrário da metafísica da ausência (desconstrução), que angustia e nos faz conscientes de que não podemos possuir nenhum sentido em plenitude. Sua defesa dessa metafísica, porém, é enganosa, pois tem este objetivo: que a desconstrução perdure para que, em alguma medida, a desconstrua.

29 BEUCHOT, Hermenéutica analógica, símbolo, mito y filosofía. 
que possa universalizar validamente, sem cair na univocidade que a filosofia científica quis, e que se mostrou irrealizável”30.

\section{Sua metodologia}

Para atingir o que foi exposto acima, argumenta Beuchot, a hermenêutica requer uma metodologia, ainda que esta seja muito geral, já que tem que ver com princípios e regras demasiadamente amplos. Ora, devido ao fato de que a hermenêutica esteve tradicionalmente associada à sutileza, seguindo OrtizOsés, ele propõe que essa metodologia consista em três passos, os quais são, ao mesmo tempo, três modos de sutileza: 1) subtilitas implicandi, 2) subtilitas explicandi, e 3) subtilitas applicandi. Assim como Ortiz-Osés, Beuchot translada esses três momentos à semiótica da seguinte maneira: o primeiro, à sintaxe - coerência entre os signos -, o segundo, à semântica - sentido textual -, e o terceiro, à pragmática - relevância contextual. Note-se, porém, que, contrariamente ao autor que ele segue e que translada o primeiro momento à semântica, Beuchot ${ }^{31}$ translada-o à sintaxe, uma vez que "nesse primeiro passo, vai-se ao significado textual ou intratextual e inclusive intertextual". Como ele argumenta acertadamente, isso se deve ao fato de que é o significado sintático que é analisado em primeiro lugar no processo interpretativo; sem ele, não pode haver semântica nem pragmática ou, mais claramente, sem ele, em primeira instância, não se pode conhecer o sentido do texto nem se pode contextualizá-lo, sem que ele seja violado ou lhe seja imposto um sentido que seja alheio ao seu ${ }^{32}$. Em suas próprias palavras:

De fato, a implicação é eminentemente sintática, por isso a fazemos corresponder a essa dimensão semiótica, e na verdade ocupa o primeiro lugar. Depois da formação e transformação sintáticas, que são implicativas por excelência, virá a subtilitas explicandi, correspondendo à semântica.

Aqui se vai ao significado do texto mesmo, não já como sentido, mas como

\footnotetext{
${ }^{30}$ BEUCHOT, Tratado de hermenéutica analógica, p. 107.

${ }^{31}$ Ibid., p. 24.

${ }^{32}$ É verdade que a tendência geral de alguns intérpretes, inclusive ilustrados como Leo Apostel - a quem o próprio Beuchot alude -, é passar por alto a análise do texto no afã de contextualizá-lo. Isso, porém, não quer dizer que seja o proceder interpretativo correto, ainda mais quando se trata de hermenêutica bíblica, porque é o sentido ou a mensagem (do autor) do texto, não do intérprete, o que se contextualiza por ser o que é normativo; daí que seja necessário estar consciente de que, antes de contextualizar o texto, deve-se discernir, da melhor maneira possível, seu sentido, mesmo quando as dificuldades hermenêuticas que medeiam essa tarefa impeçam uma compreensão exata e total desse sentido. Como Beuchot argumenta: "Na ordem de análise, estuda-se primeiro a dimensão sintática, que é a mais independente; depois, a dimensão semântica, que depende da anterior, e, no final, a pragmática, que depende das duas"; Perfiles esenciales de la hermenéutica, p. 25, nota 15. Contudo, segundo afirmamos, ainda que o argumento hermenêutico teórico de Beuchot seja correto, e apesar de argumentar o contrário, tende a conceder mais ao leitor e, com isso, à autonomia do texto e ao equivocismo.
} 
referência, ou seja, em sua relação com os objetos, e por isso é onde se descobre qual é o mundo do texto, isto é, se vê qual é seu referente, real ou imaginário. E finalmente vai-se à subtilitas applicandi, correspondente à pragmática (aquilo que é o mais propriamente hermenêutico), na qual se leva em conta a intencionalidade do falante, escritor ou autor do texto e se acaba de inseri-lo em seu contexto histórico-cultural. Isso coincide ainda com três tipos de verdade que se encontram no texto: uma verdade sintática, como pura coerência, que pode ser tanto intratextual (interior ao texto) como intertextual (com outros textos relacionados); uma verdade semântica, como correspondência com a realidade (presente ou passada) ou com algum mundo possível (futuro ou imaginário) ao qual o texto alude, e uma verdade pragmática, como convenção entre os intérpretes (e inclusive com o autor) a respeito do que foi argumentado e persuadido na interpretação, ainda que contenha elementos extratextuais (subjetivos ou coletivos) ${ }^{33}$.

Assim, ainda que parecesse limitar a contextualização - ou, como ele a chama, a aplicação da mensagem do texto - ao contexto histórico de seu autor $^{34}$, Beuchot sustenta que o método da hermenêutica é a sutileza e a penetração em suas três dimensões semióticas, que se vão constituindo e ampliando de maneira viva: 1) implicação ou sintaxe, 2) explicação ou semântica, e 3) aplicação ou pragmática. Se, para Beuchot, o ato interpretativo é um ato em que o intérprete é um sujeito ativo diante do texto, é de se

\footnotetext{
${ }^{33}$ BEUCHOT, Tratado de hermenéutica analógica, p. 25.

${ }^{34}$ Beuchot argumenta que a "aplicação" é a tarefa que vem depois do trabalho sintático (exegético) e consiste em traduzir ou transladar ao intérprete mesmo - e, acrescentaria, à sua realidade histórica - o que pôde ser a intenção do autor do texto. Ainda que ele não o explicite, com essa definição de aplicação, sublinha, por um lado, a tarefa fundamental constante de uma hermenêutica latino-americana: derivar, com base em seu próprio contexto (não com base em um contexto estrangeiro) as perguntas, linguagem, critérios e metodologia para seu trabalho exegético e teológico; é que uma hermenêutica bíblica fiel e responsável não fica apenas no sentido original do texto; ela é uma hermenêutica metafísica (contextualizada), segundo o sentido que Beuchot dá a esse termo. Por outro lado, com essa definição de aplicação, Beuchot sublinha três coisas importantes, as quais valeria a pena ressaltar: 1) o papel ativo do intérprete, 2) que é este quem - em diálogo com o texto e seu autor - no fim das contas, define o sentido do texto, e 3) que o ato hermenêutico é na realidade um ato tradutivo, interpretativo ou, se quisermos, explicativo e subjetivo, ainda que nunca niilista ou cético, uma vez que o texto está longe de ser uma entidade absoluta ou hipostática sem autor (cf. RICOEUR, Teoría de la interpretación, p. 43) e a intenção deste, apenas volitiva, psicológica e irracional, se aceitamos que ela é também cognoscitiva. Ainda que ele não seja um hermeneuta bíblico, argumenta que a "prudência" nos ajuda a buscar a verdade textual - a intenção do autor do texto - e a aplicar essa verdade à situação do intérprete; Hermenéutica analógica, símbolo, mito y filosofía, p. 85; Tratado de hermenéutica analógica, p. 34; Perfiles esenciales de la hermenéutica, pp. 16-17; apesar de nos deixar ver a relação que a hermenêutica deve ter com a metafísica, sua compreensão de "aplicação" não apenas é pouco trabalhada, mas é também limitada e confusa; esta pode ser uma das razões por que a identifica com a função própria do processo exegético que é o que deve levar-nos ao que ele argumenta da aplicação: "Com a aplicação pragmática, chega-se a essa objetividade do texto que é a intenção do autor"; Perfiles esenciales de la hermenéutica, p. 26.
} 
esperar que, seguindo Peirce e Popper, veja esse ato como abdutivo, hipotético-dedutivo, de conjectura-refutação ou de tentativa-erro; obviando os elementos semióticos aos quais faz alusão constantemente - os quais considero que pouco contribuem para a discussão e para o ato interpretativo em si ${ }^{35}$, isso significa que o intérprete, seguindo o que, na interpretação bíblica, se chama de "espiral hermenêutica" ${ }^{36}$, emite sentidos hipotéticos do texto aos quais se deve aplicar a suspeita hermenêutica.

Pode-se ver, então, que, segundo Beuchot, no ato interpretativo, confluem os três elementos clássicos do ato hermenêutico: 1) o intérprete (ouvinte ou leitor), 2) o autor (ou falante), e 3) o texto (ou mensagem); obviamente, é neste último que os dois primeiros se encontram, já que é o veículo para a transmissão da mensagem. É aqui que a proposta hermenêutica de Beuchot mostra mais claramente sua natureza analógica; contrariamente aos hermeneutas objetivistas e subjetivistas radicais, mesmo dando certa prioridade ao leitor e, por isso, à subjetividade, Beuchot procura chegar "a uma mediação prudencial e analógica na qual a intenção do autor se salvaguarda graças à maior objetividade possível, mas com a advertência de que nossa intencionalidade subjetiva se faz presente" ${ }^{\prime \prime 37}$.

Ora, essa mediação prudencial e analógica significa, então, uma opção pela intenção do texto e, certamente, do autor, mas consciente de que a interpretação fica incompleta quando se explora apenas aquela ou se privilegia a univocidade e se castiga com isso a equivocidade. É que, argumenta Beuchot, o texto e o autor são lidos com base em nossa situação, em nosso marco de referência ou, como diria Gadamer, em nossa tradição atual própria ${ }^{38}$; isso

\footnotetext{
${ }^{35}$ Por exemplo, seguindo U. Eco, Beuchot distingue, no texto, um autor empírico e argumenta que é aquele que de fato deixa um texto com erros e com intenções, às vezes, equívocas. Entretanto, concordar que o texto bíblico contém intenções equívocas não é o mesmo que argumentar que ele contém erros; mesmo que esta perspectiva, baseada no status ontológico desse texto, não negue as dificuldades históricas que se possam encontrar nele, já que, como se disse exaustivamente, ele não é um manual de história, nem de teologia, como quereriam os historiadores, os teólogos e os filósofos modernos e pós-modernos.

${ }^{36} \mathrm{Ou}$ "círculo hermenêutico", como o chamam outros. Já que todo intérprete aproxima-se com mais de uma pré-compreensão - conhecimento antecipado - ao texto, a interpretação deve modificar essa pré-compreensão, o que conduzirá a uma nova autocompreensão do intérprete. Assim sendo, o intérprete, a partir de sua nova précompreensão, interroga novamente o texto, e o resultado disso é uma nova modificação da pré-compreensão e um novo entendimento do texto; ver G. REYES, "La historicidad del texto y el papel del texto en la interpretación poética”, Kairós (2001/ n.29) 68-69; seguindo J. L. Segundo, Stam (em "La Biblia, el lector y su contexto histórico", Boletín Teológico [1983/nn.10-11] 27-72), entende por círculo hermenêutico uma circulação dinâmica entre a leitura do texto bíblico e a leitura constante da realidade contemporânea, algo fundamental para uma hermenêutica evangélica contextual.

${ }^{37}$ BEUCHOT, Tratado de hermenéutica analógica, p. 28.

${ }^{38}$ Isto é, o marco histórico, cultural, religioso que, como já o sublinhamos, influi poderosamente na interpretação do texto.
} 
implica ser impossível evitar imiscuir a própria subjetividade e os erros de compreensão, e recuperar a intenção exata e total do autor. Contudo, o que foi dito antes não significa, acrescenta Beuchot, que o leitor - empírico, que não sempre é o hermeneuta - deva ter prioridade, de tal maneira que possa sentir-se livre de criar ou recriar o sentido do texto segundo seu gosto e conveniência, sem esforçar-se por captar, da melhor maneira possível, o que foi intencionado pelo autor - como o faria, segundo Beuchot, o leitor ideal - esquecendo que essa mensagem (que é o mais fácil de captar, comparado com a intenção, quando esta não é explícita) ${ }^{39}$ ainda pertence a esse autor. É que,

\begin{abstract}
se temos de falar de alguma "intenção do texto", temos que situá-la no cruzamento das duas intencionalidades anteriores [a do autor/texto e a do leitor]. Temos que nos dar conta de que o autor quis dizer algo, e o texto - ao menos em parte - ainda lhe pertence. Deve-se respeitá-lo. Mas devemos também dar-nos conta de que o texto já não diz exatamente o que o autor quis dizer; colocou nova base para sua intencionalidade ao encontrarse com a nossa [a do leitor]. Nós o fazemos dizer algo mais, isto é, dizernos algo... Assim, a verdade do texto compreende o significado ou a verdade do autor, e o significado ou a verdade do leitor vive da tensão entre ambos, de sua dialética. Poderemos conceder mais a um ou ao outro (ao autor ou ao leitor), mas não poderemos sacrificar um no altar do outro ${ }^{40}$.
\end{abstract}

Assim, para Beuchot, o desligamento total do texto do horizonte finito vivido por seu autor é relativo. Isso é assim, já que, coincidindo com Ricoeur ${ }^{41}$, afirma que o texto continua sendo um discurso contado por alguém (autor) para alguém (leitor/es) a respeito de algo (referência ou assunto de que trata); consequentemente, ele ainda pertence a seu autor (esse alguém), que o escreveu inserido dentro de seu próprio contexto histórico e cultural, com um fim comunicativo e não apenas estético-literário. É assim que Beuchot contribui para um equilíbrio analógico que não apenas limita a libertação total do texto de seu autor e de seu contexto, mas que também desconstrói certas tendências hermenêuticas pós-modernas, inclusive algumas bíblicas ${ }^{42}$.

\footnotetext{
${ }^{39}$ Beuchot distingue quatro classes de intenções em um texto: 1) consciente e explícita, 2) consciente e tácita, 3) inconsciente e explícita, e 4) inconsciente e tácita; das quatro, a primeira é a mais fácil de captar, ainda que a terceira seja também factível, com base, por exemplo, na psicanálise, tal como costumam fazer certos críticos literários freudianos com textos especialmente poéticos, os quais fazem o autor dizer perspectivas e tendências, inclusive sexuais, recônditas de seu ser e até, talvez, não intencionadas por ele. Eu prefiro falar de "posição de autor": o sistema de ideias, valores e fé, presente em toda obra literária genuína, mesmo na ficção.

${ }^{40}$ BEUCHOT, Tratado de hermenéutica analógica, p. 28.

${ }^{41}$ RICOEUR, Teoría de la interpretación, pp. 38-50.

${ }^{42}$ Ver DE WIT, En la dispersión el texto es Patria.
} 


\section{Os passos do trabalho hermenêutico}

O trabalho hermenêutico de interpretação é outro elemento sobressalente e complementar na proposta hermenêutico-filosófica de Beuchot. Desconstruindo a tendência univocista e equivocista, Beuchot sustenta que interpretar um texto não é um trabalho instantâneo nem definitivo, mas "um processo de compreensão, que cala em profundidade, que não fica na intelecção instantânea e fugaz ${ }^{\prime \prime 3}$. O trabalho de interpretação é, pois, segundo ele, um processo durante o qual o intérprete assume a tarefa de compreender um texto determinado, aprofundar sua compreensão e ser capaz de explicar, mas também, eu diria, de suspeitar dessa compreensão.

Nesse processo, em que compreender é explicar, e explicar é compreender, o que surge primeiro diante desse dado e desse sujeito que o texto é, é uma pergunta interpretativa que requer, ao mesmo tempo, uma resposta igualmente interpretativa; enquanto a pergunta é um juízo em prospectiva ou projeto, a resposta é um juízo interpretativo, ou uma hipótese que deva ser comprovada por meio de uma argumentação interpretativa e, posteriormente, ser elevada ao nível de tese.

O fim da pergunta anterior é ajudar o intérprete a compreender o texto, e pode ser: Que significa esse texto? Que quer dizer? A quem é dirigido? A resposta, especialmente às duas primeiras perguntas, como já se disse, exige uma argumentação interpretativa por meio da qual o que se afirma ser o sentido do texto deixa de ser mera hipótese, já que este se transforma em tese uma vez que foi comprovada ou avalizada pela ajuda da prudência (phrónesis) ${ }^{44}$.

\footnotetext{
${ }^{43}$ BEUCHOT, Compendio de hermenéutica analógica, p. 12.

${ }^{44}$ Como já disse, para Beuchot, além de ciência e arte, a hermenêutica é prudência, já que, seguindo Gadamer, sustenta que, no momento de definir o sentido de um texto, o intérprete delibera em torno às diferentes interpretações rivais ou possíveis que poderiam surgir do ato interpretativo; o fim dessa deliberação é escolher dentre todas elas a melhor ou, talvez, as melhores e, assim, chegar a um juízo interpretativo adequado e responsável. Dever-se-ia recordar que, por exemplo, na época de Aristóteles, a prudência era usada na ação de ponderar os prós e os contras em uma situação determinada, a fim de chegar aos fins propostos. Gadamer e Beuchot, por sua parte, aplicam-na por analogia ao texto, conscientizando-nos assim a usar a prudência na interpretação textual. Desse modo, portanto, ainda que essa maneira de pensar implique que a hermenêutica careça de regras ou de método - razão pela qual ela deixaria de ser ciência -, Beuchot sustenta que não necessariamente é assim, já que a hermenêutica pode ter regras gerais de procedimento, ainda que estas não sejam determinantes, uma vez que nem sempre elas poderiam guiar a uma interpretação responsável. Contudo, seguindo Gadamer, que renuncia às regras interpretativas, ele anima a cultivar a hermenêutica como quem cultiva a virtude da prudência; cf. Perfiles esenciales de la hermenéutica, pp. 19-20.
} 
De modo que, para Beuchot, os passos do trabalho hermenêutico de interpretação pareceriam reduzir-se a um só ${ }^{45}$. Além disso, como já o afirmei, ele opina que o sentido ou mensagem do texto será sempre aproximado, uma vez que, segundo ele, a hermenêutica analógica tende a dar maior espaço à intromissão do intérprete e, por isso, de sua subjetividade ${ }^{46}$.

\section{Síntese}

A hermenêutica é arte e ciência da interpretação, inclusive de textos que vão mais além da palavra e do enunciado. $\mathrm{O}$ objeto da hermenêutica são principalmente esses textos e seu objetivo é a compreensão deles. Ela possui uma metodologia que se resume em três modos de sutileza: a subtilitas implicandi (busca de uma compreensão da sintaxe do texto), a subtilitas explicandi (busca da semântica ou de uma compreensão do sentido do texto) e a subtilitas applicandi (busca da pragmática ou de uma contextualização do texto). Ainda que seja impossível recuperar exata e totalmente a intenção do autor, em todo o processo interpretativo - no qual sempre está presente a subjetividade do autor e do leitor - confluem três elementos que são importantes para recuperar algo dessa intenção, se se aceita que o texto ainda pertence a este. Esses três elementos são o texto, o autor e o leitor.

Os passos do trabalho hermenêutico de interpretação consistem basicamente em estar consciente de que, diante do texto, o que surge primeiro é uma pergunta interpretativa que exige, ao mesmo tempo, uma resposta interpretativa. Essa pergunta interpretativa específica é: Que significa ou que quer dizer esse texto? A resposta a ela, que é um juízo interpretativo, é, em primeira instância, uma hipótese que deve ser comprovada por meio da prudência; uma vez comprovada, é elevada ao nível de tese, ou seja, passa a ser considerada como um sentido do texto possível e aproximado, e do qual se deve suspeitar.

\footnotetext{
${ }^{45}$ Note-se como as outras perguntas que Beuchot inclui - "Que me diz?" e "Que diz agora?" - deixariam ver que ele possivelmente estivesse pensando também na contextualização do texto. Entretanto, em sua proposta geral, ele a passa por alto, esquecendo assim que é esta que completa o processo hermenêutico, por ser sua fase final; G. REYES, "De la interpretación a la contextualización del género narrativo bíblico: Apuntes para una hermenéutica filosófica literaria", in O. CAMPOS (org.), Teología evangélica para el contexto latinoamericano, Buenos Aires: Kairós, 2004, pp. 83-104.

${ }^{46}$ Contudo, dever-se-ia recordar que Beuchot não advoga por uma interpretação relativista niilista, já que a interpretação analógica que ele propõe lhe impede obter, por um lado, um sentido univocista (um único sentido, considerado "o" verdadeiro) próprio da hermenêutica positivista e, por outro, um equivocista (múltiplos sentidos e até contraditórios) próprio da hermenêutica pós-moderna. Contudo, Beuchot pareceria inclinar-se mais por este último sentido, apesar de afirmar: "eu gostaria de defender ainda a objetividade, mesmo que seja de uma maneira moderada"; Perfiles esenciales de la hermenéutica, p. 49.
} 
A ênfase no equilíbrio analógico-epistemológico que se pode perceber ao longo de toda a proposta hermenêutica de Beuchot é uma de suas contribuições mais substanciais. Ao longo de toda ela, contudo, e ainda que se proponha como uma hermenêutica contextual, pareceria esquecer dois elementos substanciais do trabalho interpretativo: a suspeita hermenêutica e a contextualização do sentido possível do texto como a fase final desse trabalho interpretativo.

\title{
IV. Hermenêutica e epistemologia analógica bíblica
}

Até onde lhe seja possível, como discípulo/a do Senhor e servo/a da Palavra de Deus, o/a exegeta esforça-se por entender com fidelidade a mensagem original do texto dentro de seu próprio contexto histórico original ${ }^{47}$, a fim de encarná-lo finalmente no mundo contemporâneo ${ }^{48}$. Essa tarefa, não

\begin{abstract}
${ }^{47}$ Seguindo Ricoeur e seu pressuposto da autonomia total do texto - e seu consequente excedente ou superávit de sentido que o autor não pôde prever -, há quem seja de opinião de que a hermenêutica deva libertar-se dos três mitos historicistas propugnados pela hermenêutica romanticista e que perduraram até hoje: 1) a mente do autor, 2) o leitor original, e 3) o sentido original; cf. J. STAM, "La Biblia, el lector y su contexto histórico", Boletín Teológico (1983/nn.10-11) 27-72; S. CROATTO, Hermenéutica Bíblica, Buenos Aires: Aurora, 1984; DE WIT, En la dispersión el texto es Patria. Ainda que, por um lado, é um mito crer que se possa entender um autor ou autora melhor do que ele ou ela se entendeu, e, por outro, que as palavras e seu significado mudam constantemente à luz das mudanças sociais, sou de opinião, como Beuchot, de que o texto ainda pertença a seu autor ou autora, apesar de ele ou ela já não existirem e de que o sentido que se procura é o do texto, e não o de seu autor; é que os autores desejaram comunicar uma mensagem a seus leitores e provocar neles uma resposta, usando como veículo de comunicação a linguagem, inclusive poética. De modo que, sem negar a contribuição atual das ciências da linguagem, o texto, pelo menos o bíblico, não é autônomo totalmente com relação a suas circunstâncias históricas em que foi produzido, nem de seu autor ou autora e tem, portanto, um sentido que comunicar, que é a meta do processo interpretativo, como o afirmarei em seguida; ver W. KLEIN / C. BLOMBERG / R. HUBBARD, Introduction to Biblical Interpretation, Nasvilhe: Thomas Nelson, 1993, pp. 167-209.

${ }^{48}$ Como se terá percebido, em toda essa obra, parti do pressuposto de que a Bíblia é a Palavra revelada de Deus, inspirada plena, verbal e dinamicamente pelo Espírito Santo e, portanto, normativa para todos os tempos e em todo contexto. Daí a responsabilidade do/a exegeta, e de quem escute essa Palavra, não apenas de responsavelmente interpretá-la, obedecer-lhe e proclamá-la, mas também de contextualizála, ou seja, encarná-la na realidade contemporânea; essa contextualização obedece ao fato de que os leitores e ouvintes dessa Palavra não vivem nem "missionam" em um vazio ou dentro de uma bolha de proteção, mas em situações históricas concretas de pobreza, injustiça, racismo, violência, sexismo, opressão e outros tantos antirreinos. Essa Palavra, então, deve chegar aos ouvintes em termos de sua própria situação cultural e histórica. Em circunstâncias como essas, nem a hermenêutica mais individualista ou escapista quererá isolar a Palavra dessas circunstâncias. De modo que sustentar que a meta da hermenêutica é discernir o sentido original do texto não necessariamente significa que se deveria ficar no passado histórico (o "por trás") desse texto; tampouco significa negar a possibilidade de vários sentidos do texto analogicamente discernidos, pois é precisamente isso que vamos propor em seguida.
\end{abstract}


obstante, é complexa, já que em meio a ela encontram-se problemas hermenêuticos que exigem ser esclarecidos e tomar uma postura em relação aos mesmos. Entre esses problemas está o epistemológico.

No campo protestante evangélico, aceita-se geralmente que o dito anteriormente deve ser a meta do intérprete e de sua tarefa interpretativa; isto é, até onde lhe seja possível, sua meta deve ser discernir a mensagem tal como o teriam entendido os leitores originais. $\mathrm{O}$ pressuposto que subjaz a esse princípio hermenêutico filosófico é não apenas que é possível entender a mensagem do texto, mas que também Deus comunicou a seu povo uma mensagem nesse texto, do qual espera uma resposta como efeito dessa mensagem $^{49}$.

Certamente, como qualquer outro ser humano, e com a lente cultural própria, cada escritor/editor bíblico teria querido comunicar por meio do texto que escreveu um conteúdo entendível que pudesse produzir um efeito transformador nos leitores de todos os tempos. E que Deus quis que sua revelação escrita funcionasse como uma janela através da qual se pudesse ver o mundo textual e cultural e ideológico do texto e sua mensagem.

Em uma perspectiva hermenêutica, o que foi dito anteriormente é inegável, tanto quanto ter, como meta da tarefa interpretativa, discernir e entender da melhor maneira possível essa mensagem histórica original ${ }^{50}$. Entretanto, deveríamos perguntar se cada um desses autores/editores teria querido realmente comunicar uma mensagem única e clara ou, em sua falta, múltiplas, contraditórias e até mística ou escondida, como propõem respectivamente as hermenêuticas univocista e equivocista. Responder a essas perguntas é um dos grandes desafios com que se enfrenta hoje a hermenêutica contemporânea, incluindo a bíblica. Contudo, considero que a hermenêutica analógica, mesmo não sendo uma receita totalmente fácil, pode ajudar-nos a respondê-las responsavelmente e até onde seja possível. Façamos a tentativa.

\footnotetext{
${ }^{49}$ Cf. W. KAISER, Toward an Exegetical Theology: Biblical Exegesis for Preaching and Teaching, Grand Rapids: Baker, 1998; KLEIN / BLOMBERG / HUBBARD, Introduction to Biblical Interpretation, p. 187.

${ }^{50} \mathrm{Ou}$ seja, o que é comunicado através das palavras e da estrutura gramatical do idioma em que foi plasmado e com a perspectiva cultural e ideológica própria da época. Já que é a única coisa que podemos recuperar, essa mensagem textual, inclusive por meio da poética ou de artifícios artísticos, deve ser a meta da tarefa interpretativa, a qual espera que essa mensagem aproxime-se da melhor maneira possível da intenção de seus autores/editores; desse modo, não perdemos de vista os autores, e a mensagem fica centrada não apenas no texto, mas também neles, pois ambos são veículos da intenção de Deus.
} 
Beuchot opina corretamente ${ }^{51}$ que, através da história, a hermenêutica analógica acompanhou sutilmente a univocista e equivocista na tarefa interpretativa acrescentaria, inclusive bíblica. E nos anos recentes, graças à recuperação e à potencialização que dela fizeram, por exemplo, Gadamer, ela veio posicionarse tanto na hermenêutica como na filosofia, psicologia e em outros campos contemporâneos do saber ${ }^{52}$. Por essa razão, poder-se-ia argumentar que a interpretação analógica estaria contribuindo tanto para evitar as debilidades e perigos das interpretações univocistas e equivocistas extremas quanto para impulsionar o equilíbrio analógico que tanto urge em todos esses campos. Antes de vermos essa contribuição que a analogia poderia fazer em nosso campo de interesse - a hermenêutica bíblica -, vejamos primeiro o que se entende por analogia e, posteriormente, qual sua contribuição neste campo.

A analogia é uma virtude. E ela pode ser de proporção e de atribuição; a primeira, opina Beuchot ${ }^{53}$, denomina-se assim porque

[e]stabelece relações entre as porções, a:b::c:d, e pode ser própria, como quando se diz: "O instinto é para o animal o que a razão é para o homem", assim como também pode ser imprópria ou [analogia] metafórica, como quando se diz: "O riso é para o homem o que as flores são para o prado", e assim entendemos a metáfora "O prado ri". A segunda, a de atribuição, estabelece uma hierarquia de propriedade na atribuição de um predicado ou vários sujeitos, como quando se diz "são", atribui-se primariamente ao organismo, assim pode-se dizer que um homem está são [analogado principal ou atribuição mais própria]; mas também se pode atribuir, secundariamente, ao alimento, ao remédio, ao ambiente e inclusive à amizade [analogados secundários ou atribuição por relação], pois chegamos a dizer que uma amizade é sã, ou que não o é; mas isso já é em sentido impróprio. Por isso, vemos que há uma hierarquia de atribuições, na qual a saúde é predicada de modo mais próprio ao organismo, e de modo menos próprio ao alimento, e de modo menos próprio ao remédio, e de modo menos próprio ao ambiente, e de modo menos próprio ainda à amizade, assim: descendo desde o mais próprio ao menos próprio. E, contudo, é válida a atribuição em todos os casos, apenas que em uns mais e em outros, menos.

${ }^{51}$ BEUCHOT, Compendio de hermenéutica analógica, pp. 24-37, 40-142; BEUCHOT et alii, Hermenéutica analógica y hermenéutica débil, p. 16.

${ }^{52}$ Gadamer tê-la-ia potencializado com sua ênfase nessa virtude intuitiva sutil e equilibrada: a "prudência" (phrónesis); como já se disse, a "prudência" induz normalmente a deliberar diante de uma determinada situação e, com sua ajuda, ponderamse os prós e os contras de uma ação determinada até se chegar finalmente a uma decisão sobre o que seria melhor fazer. No processo interpretativo e de compreensão de um texto, espera-se que ela faça algo semelhante: ajudar o intérprete a deliberar, equilibrada ou analogicamente, entre interpretações rivais, que o leve finalmente a decidir-se pela ou pelas mais apropriadas, mas que façam, em alguma medida, justiça aos dados do texto; ver BEUCHOT, Hermenéutica analógica, símbolo, mito y filosofía, p. 58. Para isso, a exegese aqui é fundamental.

${ }_{53}$ BEUCHOT, Compendio de hermenéutica analógica, pp. 40-41; cf. BEUCHOT, Hermenéutica analógica, símbolo, mito y filosofía, pp. 20-24. 
Todos esses tipos de analogia - de proporção própria e de proporção imprópria ou metafórica, e de atribuição principal e secundária - constituem o modelo analógico. Aplicada ao trabalho hermenêutico bíblico, a analogia de "proporção" - que associa termos que têm um significado em parte comum e em parte distinto ${ }^{54}$ - permitiria discernir vários sentidos válidos do texto, porque cada um deles seria proporcionalmente semelhante uns aos outros. Desse modo, é possível aplicar em vários deles a "proporção própria", a fim de que se possa resgatar o lado literal ou objetivo da analogia; em outros, poder-se-ia aplicar a "proporção imprópria", a fim de que se possa resgatar o lado metafórico ou subjetivo dessa mesma analogia (analogia metafórica). Assim, por um lado, teríamos sentidos do texto que poderiam ser legítimos, e, por outro, sentidos dos quais, ainda que possíveis, deveríamos suspeitar, por serem produtos do lado subjetivo da analogia. É aqui onde esse ângulo artístico e prudencial da tarefa interpretativa entra em função; é aqui também que se deveriam aplicar, além da suspeita e da prudência, os critérios que, por exemplo, Klein, Blomberg e Hubbard ${ }^{55}$ su- $^{-}$ gerem para validar uma interpretação.

De igual modo, aplicada à hermenêutica, a analogia de "atribuição" permitir-nos-ia discernir vários sentidos legítimos do texto. Mas, desta vez, hierarquizados, por assim dizer, segundo se depreendam legitimamente do texto, sem que lhe sejam impostos ${ }^{56}$. Essa hierarquização é levada a cabo priorizando aqueles que sejam mais legítimos que outros, mesmo quando todos possam pertencer ao conjunto de sentidos considerados válidos, como sucede quando se interpreta um texto narrativo a partir de ângulos diferentes. Assim se poderia evitar uma interpretação excessivamente subjetivista e equivocista, ou seja, que tenda tanto a basear-se excessivamente na experiência ou na intuição quanto a legitimar sentidos estranhos ao texto e ademais absurdos ou contraposto ${ }^{57}$. Para evitar tal interpretação e tais tendências, também aqui é aconselhável validar especialmente aqueles sentidos hierarquizados ou considerados mais válidos que outros.

\footnotetext{
54 Como em "a razão é para o homem o que os sentidos são para o animal”. O significado comum é que tanto o homem quanto o animal possuem uma característica que os distingue (razão e sentidos, respectivamente). O significado distinto é que um possui razão e o outro, sentido. Assim se poderia ver o lado literal ou objetivo e, ao mesmo tempo, o metafórico ou subjetivo da analogia.

${ }^{55}$ KLEIN / BLOMBERG / HUBBARD, Introduction to Biblical Interpretation, pp. 201209.

${ }^{56}$ Em Perfiles esenciales de la hermenéutica, p. 27, Beuchot observa que a analogia de proporção implica diversidade de sentidos. Mas uma diversidade estruturada coerentemente, resultando uma interpretação respeitosa não apenas da diversidade, mas também, na minha opinião, do texto, não perdendo de vista a proporção, nem tentando cair no desproporcionado ou na dispersão equívoca relativista do significado. ${ }^{57}$ Como alguns exegetas, considero legítimo o uso da intuição como fase primeira do processo de interpretação de um texto. $\mathrm{O}$ erro é, como sucede frequentemente, ficar nessa fase e não passar à segunda, que a constitui em uma exegese responsável. Esse erro é o que dá lugar a interpretações alheias ao texto e frequentemente absurdas.
} 
Ainda que falte muito por desenvolver quanto à estrutura, à função e à contribuição da hermenêutica analógica, considero que é nesse ponto que se pode ver como ela contribui filosoficamente de duas maneiras válidas, em suma, em nosso processo de interpretação bíblica. A primeira é provendonos de vários sentidos legítimos do texto, não somente de um único que seja claro, preciso e objetivo; assim nos impede de cair ingenuamente no unívoco, o qual considera ser possível recuperar o significado total e exato de um texto, autor ou falante. A segunda, permitindo-nos, nesse mesmo processo, esse equilíbrio ou ponto intermediário prudencialmente analógico, ao ajudar-nos a evitar não apenas o univocismo, mas também a evitar dispersarnos no equivocismo extremo que prolifera na hermenêutica atual, muito mais se se suspeita de nossas interpretações e se ela as valida responsavelmente. Por conseguinte, ela demole as tendências univocistas e equivocistas extremas e suaviza a polêmica existente entre elas.

Destarte, entende-se que a hermenêutica analógica é um afã tanto de dominar o que o texto pode dar e sua interpretação quanto de dar lugar àquilo com que a hermenêutica tradicional frequentemente não se preocupou, mas que é algo legítimo: a participação consciente da subjetividade do intérprete. Assim, na minha opinião, a interpretação analógica permite ainda uma objetividade interpretativa maior do que a que a univocista pragmatista postula, e uma menor e mais controlada subjetividade com relação à hermenêutica equivocista relativista ${ }^{58}$.

\section{Epistemologia analógica e gênero narrativo} bíblico

O modelo epistemológico analógico de interpretação, que evita a univocidade e a caótica equivocidade, pode ajudar-nos em nossa busca por uma hermenêutica narrativa bíblica ajuizadamente equilibrada que evite, na interpretação especializada ou não, uma epistemologia tanto subjetivista, relativista, pluralista, alegórica ${ }^{59}$ e de outra índole ${ }^{60}$ quanto uma idealista, absolutista e objetivista que ultrapasse os limites, a qual pretende fazer-nos crer que podemos conhecer exaustivamente e que tudo o que é conhecido está dado, sem a participação responsável do intérprete do texto. Isso por-

${ }^{58}$ Cf. BEUCHOT, Perfiles esenciales de la hermenéutica, p. 28.

${ }^{59}$ Refiro-me aqui à hermenêutica alegórica popular ou informal em certos grupos evangélicos protestantes. É aquela hermenêutica que, vendo, em cada detalhe do texto, símbolos ocultos com mensagens ocultas, que devem ser decifradas espiritualmente e em um espírito de guerra espiritual (contra o Diabo, o "mundo" e a "carne"), deixa fora o sentido literal e histórico desse texto.

${ }^{60}$ Por exemplo, as altamente ideológico-políticas e sexistas que circulam na América Latina e em outros contextos. Entre as primeiras, estão as denominadas "hermenêuticas do genitivo" (feminista, campesina e outras). 
que, ao optar por um ponto de vista que faça maior justiça ao conhecer e ao ser que interpreta, também se fará maior justiça ao texto cuja mensagem se quer conhecer.

O resultado da opção anterior será uma hermenêutica analógica relevante para o contexto sociocultural, hermenêutico e teológico que nos cabe viver. Essa será uma hermenêutica bíblica que se esforce por discernir, ajuizada ou responsavelmente, a mensagem do texto com fins transformadores; essa tarefa é importante hoje quando nos querem convencer, não apenas de que não há critérios, nem regras nem princípios capazes de guiar a ética do ser humano e procurar sua transformação como agentes da missão de Deus ${ }^{61}$, mas também de que o conhecimento é irrelevante ${ }^{62}$. Já que nosso campo de interesse é o texto narrativo bíblico, colocaremos nosso foco nele; para tanto, é conveniente primeiro discutir sobre a natureza desse gênero.

\section{Referências bibliográficas}

BEUCHOT, Mauricio, Posmodernidad, hermenéutica y analogía, México: Universidad Intercontinental, 1996.

(1998), "Hermenéutica analógica y crisis de la modernidad". Acessado em 23 de janeiro de 2008, <http://www.uaem.mx/oferta/facultades/humanidades/ filos/Beuchot-Herme.htm.>

Tratado de hermenéutica analógica: Hacia un nuevo modelo de interpretación, México: Itaca, 2005.

Perfiles esenciales de la hermenéutica, México: Universidad Nacional Autónoma de México, 2005.

BEUCHOT, Mauricio et alii, Hermenéutica analógica y hermenéutica débil, México: Facultad de Filosofía y Letras, Universidad Nacional Autónoma de México, 2006.

BEUCHOT, Mauricio, Compendio de hermenéutica analógica, México: Torres, 2007.

Hermenéutica analógica, símbolo, mito y filosofía, México: Universidad Nacional Autónoma de México, 2007.

CROATTO, José Severino, Hermenéutica Bíblica, Buenos Aires: Aurora, 1984.

CHAVES TESSER, Carmen, "El debate teórico actual”, in José Luis GÓMEZMARTÍNEZ (org.), Más allá de la pos-modernidad: El discurso antrópico y su praxis en la cultura iberoamericana, Madrid: Mileto, 1999.

\footnotetext{
${ }^{61}$ Pretensão que permite deixar a moral ao indivíduo, a seus interesses e caprichos. Recorde-se, nessa conjuntura, nossa perspectiva do texto bíblico como Palavra autoritativa, libertadora e transformadora de Deus, seu autor final, sem que esta perspectiva implique outorgar a essa Palavra qualquer rigidez legalista.

${ }_{62} \mathrm{Em}$ certos contextos de cultura bíblico-teológica light, pode-se ver esse rechaço como quando uma pessoa pediu-me que a ajudasse a editar certo material; quando, em uma parte, lhe sugeri optar pelo verbo "ensinar", essa pessoa me respondeu: "Não, não, não! Ensinar apenas enfatiza conhecimento intelectual!".
} 
DE WIT, Hans, En la dispersión el texto es Patria: Introducción a la hermenéutica clásica, moderna y posmoderna, San José: Universidad Bíblica Latinoamericana, 2002.

FOUCAULT, Michael, Microfísica del poder, Traducción del original francés por J. Varela y F. Alvarez-Urías, Madrid: Piqueta, 1992.

KAISER, Walter, Toward an Exegetical Theology: Biblical Exegesis for Preaching and Teaching, Grand Rapids: Baker, 1998.

KLEIN, William / BLOMBERG, Craig / HUBBARD, Robert, Introduction to Biblical Interpretation, Nasvilhe: Thomas Nelson, 1993.

REYES, George, "La historicidad del texto y el papel del texto en la interpretación poética", Kairós (2001/n.29) 68-69.

"De la interpretación a la contextualización del género narrativo bíblico: Apuntes para una hermenéutica filosófica literaria", in Oscar CAMPOS (org.), Teología evangélica para el contexto latinoamericano, Buenos Aires: Kairós, 2004, pp. 83-126.

"El giro hermenéutico contemporáneo: Lectura de tendencias", Kairós (2006/n.38) 41-59.

“Verdad y racionalidad hermenéutica analógica: Exploración e implicaciones para la interpretación del texto bíblico", Kairós (2010/n.45) 81-108.

RICOEUR, Paul, El conflicto de las interpretaciones: Ensayos de hermenéutica, Traducción del original francés por A. Falcón, Buenos Aires: Fondo de Cultura Económica, 2003.

Teoría de la interpretación: Discurso y excedente de sentido, México: UIA / Siglo XXI, 2006.

STAM, Juan, “La Biblia, el lector y su contexto histórico”, Boletín Teológico (1983/ nn.10-11) 27-72.

(Tradução do original espanhol por Claudio Paul SJ)

George Reyes, pastor, é bacharel e mestre em Teologia, e mestre em Estudos Bíblicos, pelo Seminario Teológico Centroamericano (Seteca), Guatemala, América Central. É doutorando em Teologia no Programa Doctoral Latinoamericano (PRODOLA) e docente no Seminário Todas Las Naciones, Ciudad Juárez, Chihuahua, México. Autor de artigos em diversas revistas teológicas, prepara a publicação do livro Hermenéutica analógica bíblica.

Endereço: Seminario Todas las Naciones

Ciudad Juárez (Chihuahua) - MÉXICO 